This item was submitted to Loughborough's Research Repository by the author.

Items in Figshare are protected by copyright, with all rights reserved, unless otherwise indicated.

\title{
Viable pathogen aerosols produced during laser dermatology surgery - a quantified analysis
}

\section{PLEASE CITE THE PUBLISHED VERSION}

https://www.lia.org/conferences/ilsc

\section{PUBLISHER}

(C) Laser Institute of America (LIA)

\section{VERSION}

AM (Accepted Manuscript)

\section{PUBLISHER STATEMENT}

This work is made available according to the conditions of the Creative Commons Attribution-NonCommercialNoDerivatives 4.0 International (CC BY-NC-ND 4.0) licence. Full details of this licence are available at: https://creativecommons.org/licenses/by-nc-nd/4.0/

\section{LICENCE}

CC BY-NC-ND 4.0

\section{REPOSITORY RECORD}

Tyrer, John R., Lewis C.R. Jones, Jack Edwards, Alan Beswick, Delphine Bard, and Jason Britton. 2019. "Viable Pathogen Aerosols Produced During Laser Dermatology Surgery - a Quantified Analysis". figshare. https://hdl.handle.net/2134/37411. 


\title{
VIABLE PATHOGEN AEROSOLS PRODUCED DURING LASER DERMATOLOGY SURGERY - A QUANTIFIED ANALYSIS
}

Paper MP602

\author{
John Tyrer ${ }^{1}$, Lewis C. R. Jones ${ }^{1}$, Jack Edwards ${ }^{1}$, Alan Beswick², Delphine Bard², Jason Britton ${ }^{3}$ \\ 1 Wolfson School and Mechanical, Electrical and Manufacturing Engineering, Loughborough University, \\ Loughborough, Leicestershire, LE11 3TU, UK \\ 2 Health and Safety Laboratory, Harpur Hill, Buxton, Derbyshire, SK17 9JN, UK \\ ${ }^{3}$ Medical Physics Department, Leeds General Infirmary, Leeds, LS1 3EX, UK
}

\begin{abstract}
The use of laser processes for surgical, medical and cosmetic procedures has been increasing with five hundred thousand workers exposed to laser surgical smoke per year. The use of lasers introduces direct beam hazards into the environment but also generates unique hazards such as material ejected from the laser process. Within this material can be potentially harmful particulate when inhaled by humans, accompanying this particulate is a foul unwanted odour. Along with the generation of these particles it is extremely possible for viable biological organisms to be generated with the particulate. Airborne particulate matter or bio-aerosols are not just a hazard to the patient, but also to other people in the environment around the laser process.
\end{abstract}

The aim of this paper is to investigate and quantify the aerosol danger to both patients and operators when utilising lasers within surgical procedures, while suggesting a suitable initial solution. The tailored research for this aim will focus on whether a suitable extraction system can be developed and the effects that different types of lasers have on the size and visuals of any particulate generated. To determine whether there is a risk of infection and to ascertain the level of infection control, the possibility of viable bio-aerosols being detected after a laser process should be considered. The experiments are split into 3 sections; section 1 is the testing of the extraction system using a smoke generation system to ascertain visual proof of a functioning extraction system, section 2 is the testing of the effect of laser irradiance on the tissue simulant to determine the effect of varying laser types on the particulate generated and section 3 is the generation and measurement of bio-aerosols with the use of bio markers to test for survival of laser processing and transmission.

\section{Introduction}

The use of laser processes for surgical, medical and cosmetic procedures has been increasing with five hundred thousand workers exposed to laser surgical smoke per year [1]. The use of lasers introduces direct beam hazards into the environment but also generates unique hazards such as material ejected from the laser process.

The plume ejected by the laser process can contain "hair, desiccated cells (viable and non-viable cellular material), prions, or other deleterious matter. In addition to smoke plume, noxious gaseous fumes, or vapour, will be given off which may have toxic or carcinogenic constituents' [2], [3]. Within these constituents, it has been found that 'benzene, formaldehyde, acrolein, carbon monoxide and hydrogen cyanide' are present [4]. It has been shown that carbon dioxide and Nd:YAG laser both emit this plume makeup from laser procedures [5]. Bioaerosols can be generated along with airborne particles and they can contain viable organisms such as bacteria and viruses. The infectious potential of the plume is discovered within cellular clumps and red blood cells discovered during laser processes [6]. Viral strands of the STI human papillomatosis DNA (HPV) has been shown to survive laser ablation in other studies [7], [8]. This clearly indicates the need for research into possible solutions for such potential harms.

While there is little evidence on the subject, viral and cellular debris within the plume can possibly cause adverse effects to humans [9]. The potential for biologically active material to survive the laser process exists. Airborne particulate matter or bioaerosols are not just a hazard to the patient but also to other people in the environment around the laser process.

Airborne particles are generally classified by their aerodynamics diameter, where any particle less than $10 \mu \mathrm{m}$ are inhalable. The coarse fraction of particles, between 2.5 and $10 \mu \mathrm{m}$, will be deposited in the 
respiratory tract. These particles will either be coughed out or swallowed which raises further toxicology issues. Particles smaller than $2.5 \mu \mathrm{m}$ are known as insoluble fine particulate matter and will deposit in the alveolar region in the lung. These particles are cleared via 'phagocytosis by alveolar macrophages' [10]. Particles smaller than $2.5 \mu \mathrm{m}$ can also induce inflammatory and pro-thrombotic responses while promoting atherosclerosis and thermogenesis [11].

A typical example of medical laser equipment is shown in Figure 1. Anecdotally it has been reported that a foul smell is generated by this process in combination with the smoke [3]. Currently the operators would wear surgical masks, but these are more designed to protect the patient and open wounds from respiratory particles originating from the operators mouth or nose. The procedure causes the emission of potentially harmful fume, currently there is no method of effective filtration, only a poor extraction method as shown in Figure 1. Currently the extraction system functions at the edge of the process zone rather than at the source of plume, this leads to fumes potentially escaping and being inhaled by operators or the patients. The handpiece contains no optical radiation shielding, leading to potential damaging the operators eyes and is currently large and difficult to hold in lengthy procedures.
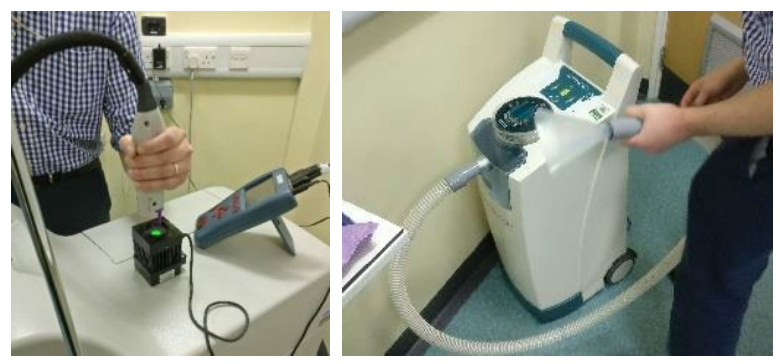

Figure 1. Current laser handpiece with standoff, and separate extraction and collection nozzle.

The aim of this paper is to investigate the potential dangers to both patients and operators when utilising lasers within surgical procedures.

The specific research questions are:

- Can a suitable extraction system be developed to provide extraction directly from the target area?

- Does the type of laser used in procedures influence the size of particulate generated?

- Is it possible for viable virus or bacteria particulate to survive laser treatment of a human tissue substitute?

\section{Method}

The experiments are split into 3 phases. Phase 1 is the testing of the extraction system using a smoke generation system. The aim of phase 1 is to determine the effectiveness of the extraction system within the hand piece, while providing suitable visual aids of extraction.

Phase 2 is the testing of the effect of laser irradiance on the tissue simulant. The aim of phase 2 is to determine the physical effects on the fume generated and porcine tissue damage from laser generated procedures.

Phase 3 is the generation and measurement of bioaerosols with the use of bio markers to test for survival of laser processing and transmission. The aim of phase 3 is to investigate whether viable virus or bacteria survives the laser treatment of porcine tissue.

Phase 1 and 3 are conducted within a controlled air chamber $(\mathrm{CAC})$ at the health and safety labs in Buxton. The lab has an internal volume of $35 \mathrm{~m}^{3}$ and has been used in previous particulate research due to it allowing repeatable tests [12]. The CAC provides consistent and reliable results due to the stable and controllable environment while providing suitable health and safety conditions.

All three phases utilise a designed handpiece prototype when it is required to extract the plume from the target area. The prototype has been designed to provide direct extraction from target area and provide the diode fibre laser with increased stability, while encasing the laser optical radiation within its tip. The prototype plume flow path when extracted within the device as shown in Figure 2.

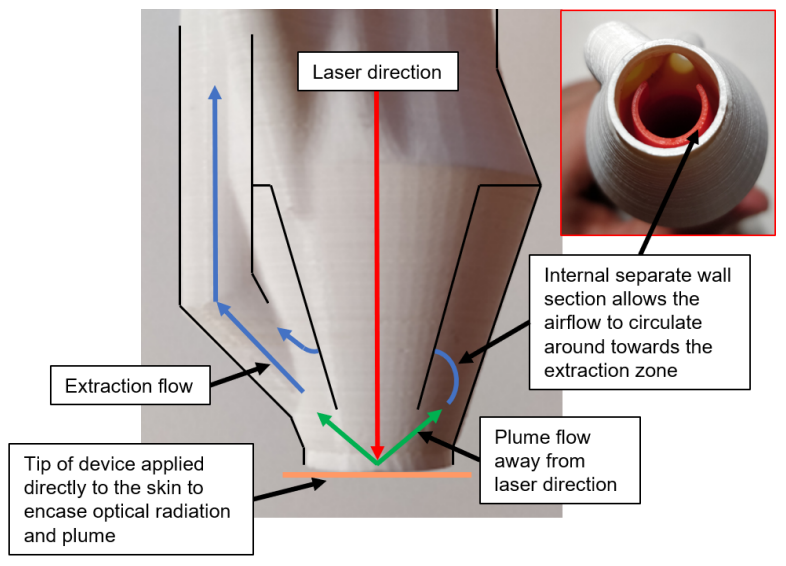

Figure 2. Handpiece with integrated extraction prototype airflow paths 


\section{Phase 1 - Smoke Generation and Extraction}

The extraction prototype is fixed in position $10 \mathrm{~mm}$ above where the smoke pencil is initiated to allow for sufficient visuals to be acquired. The extraction pump is set to $10 \mathrm{~L} / \mathrm{min}$, the pump is connected to the handpiece via $10 \mathrm{~mm}$ inner diameter (ID) tubing and the smoke is evacuated to a safe extraction method away from the CAC. To create a constant air flow through the smoke pencil, a pressure regulator was set at $0.5 \mathrm{bar}$ and connected to the smoke pencil. This is done to achieve constant smoke generation without the requirement for the operator to be in the $\mathrm{CAC}$, while also displaying the effectiveness of the extraction device. This ultimately decreases the risk to the operator as the plume generated by the smoke pencil can be irritable if inhaled [13], [14].

The ventilation smoke tube kit used in this experiment is used for tracing air currents within various systems, ranging from mine shafts to ventilation systems. The plastic tube kit contains two hermetically sealed glass ampoules, one with $0.4 \mathrm{gms}$ acetic acid sorbed on silica gel and one with $0.3 \mathrm{gms}$ ethylenediamine sorbed on pumice. When they react together ethylenediamine acetate smoke is produced. While not dangerous, if excessive exposure to the fume occurs, it can become irritable [13], [14].

\section{Phase 2 - Simulation of Medical Laser Procedure}

Utilized an $810 \mathrm{~nm}$ Biolitec diode laser, with a max power of $20 \mathrm{~W}$, fluency equal to $15 \mathrm{~J} / \mathrm{cm}^{2}$ and a $600 \mu \mathrm{m}$ fibre. The laser is currently used in medical procedures, is set to $15 \mathrm{~W}$ for the duration of these tests. The other laser used in testing Neodymium-doped yttrium aluminium garnet (Nd:YAG) laser, an Asceplion Qswitched with a wavelength of $1064 \mathrm{~nm}$. The other varying settings used by the YAG laser are fluency equal to $5 \mathrm{~J} / \mathrm{m}^{2}$, frequency of $2 \mathrm{~Hz}$, and a $4 \mathrm{~mm}$ spot size.

Fresh porcine skin is used as a substitute for human skin, due to its similar biomedical properties while being cost effective and having a similar hair follicle structure within the dermis [15]-[20]. The tissue has a similar corneum thickness to human skin of around $21-26 \mu \mathrm{m}$ [21]. While primate skin would perhaps be a better representation for human skin, it is restricted for use in research [21]. Porcine skin is far easier to obtain from abattoirs and is a very common skin substitute in relevant research areas[21]. Porcine skin is proven to have very similar histological and biochemical properties in many relevant experiments [15]-[19]. The tissue is kept stationary in each test to resemble the type of medical procedure conducted where the patient would remain stationary.
The same method is to be used for both Apply the laser to the porcine tissue for 15 seconds, then have an off time of 30 seconds. This should be repeated 5 times on a different area of tissue for consistent results. P-Trak particle counters can assess particles between $0.02 \mu \mathrm{m}$ and $10 \mu \mathrm{m}$. This is placed at the source of the porcine tissue as shown in Figure 3, along with an Optical Particle Sizer (OPS) machine. The OPS analyses data on particle numbers and their size distribution between $0.3 \mu \mathrm{m}$ and $10 \mu \mathrm{m}$. The data acquired from the OPS shows the particle counts for each size range bin, with each bin having the following ranges; Size bin 1: 0.3 to $0.5 \mu \mathrm{m}$; Size bin 2: 0.5 to $1 \mu \mathrm{m}$; Size bin 3: 1 to $2 \mu \mathrm{m}$; Size bin 4: 2 to $5 \mu \mathrm{m}$; Size bin 5: 5 to $10 \mu \mathrm{m}$.

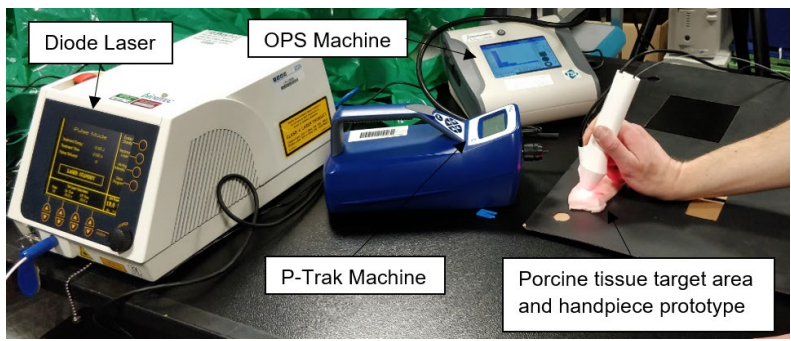

Figure 3. Simulation of Medical Laser Procedure Testing Setup

\section{Phase 3 - Bioaerosol Generation Testing}

The type of laser used for these tests is an $810 \mathrm{~nm}$ Biolitec diode laser, with a max power of $20 \mathrm{~W}$ and a $600 \mu \mathrm{m}$ fibre. The laser is currently used in medical procedures, is ideal for the experiments due to its small footprint and is provided by Jason Britton. Each treatment utilises the diode laser at a power of $15 \mathrm{~W}$, delivering 5 pulses with $15 \mathrm{~s}$ on time and 30s off time. The fibre is $1 \mathrm{~mm}$ above the pork tissue in both experimental setups as shown in Figure 4. For each organism, three tests are conducted without the extraction device and three are conducted with the device. Each test is conducted on a new cut area of the pork tissue.

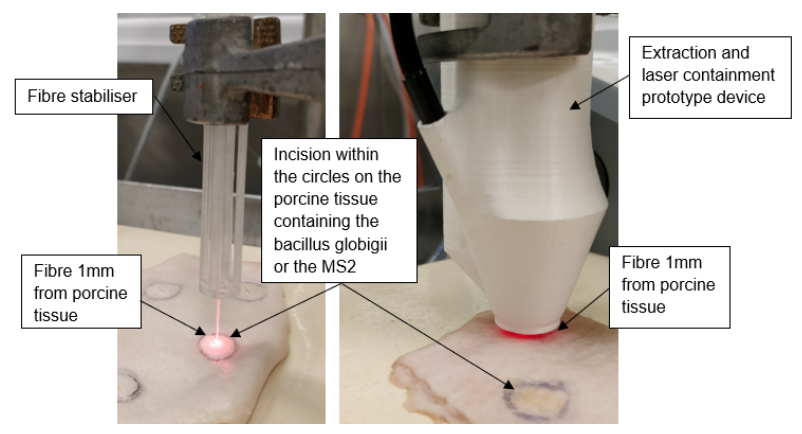

Figure 4. Bioaerosol Generation Testing Target Area (a) No Extraction (b) With Extraction 
Bacteria which can be utilised as markers within the plume are an effective way of discovering whether bioaerosol generation can survive the laser application. One form used is Bacillus globigii (full name - Bacillus atrophaeus subsp. globigii), this is a spore forming bacterial cell type. It forms hardy endospores because of induced sporulation, such as treatment with certain salts, lack of water or nutrients [22], [23]. It grows with a very characteristic colony colour and morphology, this allows it to be extremely useful as a marker organism

For Bacillus globigii, $2.0 \times 10^{10} \mathrm{cfu} / \mathrm{ml}$, the pork tissue is seeded with $20 \mu \mathrm{l}$ in spore suspension within $1-1.5 \mathrm{~mm}$ depth cuts in the pork. Where cfu stands for colony forming units, estimating the number of viable bacteria in the sample where viable is defined as the use of binary fission to multiply under controlled conditions.

Another marker that can be used is MS2, known as bacteriophage which is a virus that only infects bacteria. The virus' natural host is an E. coli bacterial cell type. This viral particle is much smaller than a bacterial cell, its 'capsid consists of a $27 \mathrm{~nm}$ hollow sphere and is formed from $322 \mathrm{~nm}$ pores'. This allows small molecules to diffuse more easily through the capsid [23].

For the MS2, $6.4 \times 10^{9} \mathrm{cfu} / \mathrm{ml}$, the Pork tissue is seeded with $20 \mu \mathrm{l}$ in suspension within $1-1.5 \mathrm{~mm}$ depth cuts in the pork. The MS2 was cultured overnight in nutrient broth containing E. coli ATCC15597, where the E. coli is removed via filtering.

AGI 30 impinger samplers and Andersen samplers (single stage and six stage) are used to take air samples and are processed using culture-based analysis. The AGI 30 impingers are pre-prepared with $20 \mathrm{ml}$ of sterile phosphate buffered saline (PBS) solution with the sampling pumps running at $12.5 \mathrm{~L} / \mathrm{min}$. One impinger is positioned in vicinity to the pork tissue, and the other impinger is placed at operator head height $(55 \mathrm{~cm})$ above the pork tissue as shown in Figure 5. They are run for one minute prior to the laser treatment, during the treatment and for a period of fifteen minutes afterwards to collect any airborne MS2 and Bacillus globigii. One set of impingers is used for each set of three tests, around one hour of sampling time. The impinger fluid is recovered and analysed for viable MS2 and Bacillus globigii.

The Andersen samplers are loaded with nutrient agar plates and the sampler pumps are running at $23.4 \mathrm{~L} / \mathrm{min}$. For the MS2 tests, single-stage Andersen samplers were used, and for the Bacillus globigii tests, six-stage Andersen samplers were used. For each test, two Andersen samplers were positioned close to the pork tissue, with one at the same level as the pork skin and the other on a stand approx. $55 \mathrm{~cm}$ higher at operator head height as shown in Figure 5. The samplers are run for the same amount of time as the impingers. At the end of each test, two new Andersen samplers were placed in position with around 20 minutes sampling time each. At the end of the test, the plates were removed from the samplers for processing.

The inline air filter used in conjunction with the extraction device is a GF/A Whatman filter. A single filter is used for the three Bacillus globigii and another for three MS2 tests.

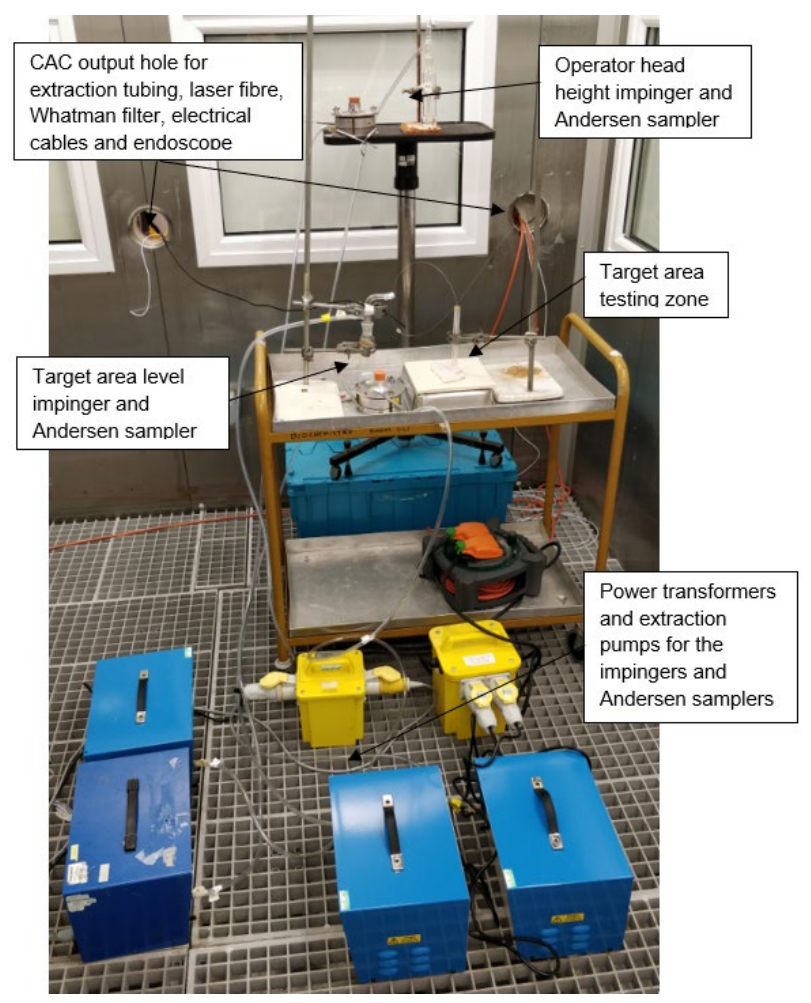

Figure 5. Bioaerosol Generation Testing Setup

For analysis of MS2 impinger results, an aliquot $(1 \mathrm{ml})$ was stored at $4^{\circ} \mathrm{C}$, to be observed later under light microscopy for any evidence of carbon particles. An aliquot $(100 \mu 1)$ was mixed with $300 \mu 1$ of an exponentially growing E. coli ATCC15597 culture and $3 \mathrm{ml}$ of semi-solid agar and plated on to duplicate nutrient agar plates. Agar plates were incubated at $35^{\circ} \mathrm{C}$ for 48 hours, and plaques counted to assess numbers of viable airborne MS2. For the Andersen samplers, the agar plates were removed from the Andersen samplers. Exponentially growing E. coli ATCC15597 (300 $\mu 1)$ and $3 \mathrm{ml}$ of semi-solid agar were mixed together and poured on to each agar plate. The plates were incubated at $35^{\circ} \mathrm{C}$ for 48 hours, and plaques counted to assess numbers of viable airborne MS2. For the extraction filter, the GF/A 
Whatman filter was immersed in $5 \mathrm{ml}$ PBS and put on a roller-shaker for $45 \mathrm{~min}$ and the same analysis is performed as with the impingers.

For analysis of Bacillus globigii impinger results, an aliquot $(1 \mathrm{ml})$ was stored at $4^{\circ} \mathrm{C}$, to be observed later under light microscopy for any evidence of carbon particles. An aliquot $(100 \mu \mathrm{l})$ was serially diluted and plated on to duplicate nutrient agar plates. The remaining sample solution was filtered on to a $0.45 \mu \mathrm{m}$ pore filter and the filter placed on to a nutrient agar plate. All agar plates were incubated at $37^{\circ} \mathrm{C}$ for 48 hours, and colonies counted to assess the numbers of viable airborne Bacillus globigii. For the Andersen samplers, the agar plates were removed from the Andersen samplers and were incubated at $37^{\circ} \mathrm{C}$ for 48 hours, and colonies counted to assess the numbers of viable airborne Bacillus globigii cells present. For the extraction filter, the GF/A Whatman filter was immersed in $5 \mathrm{ml}$ PBS and put on a roller-shaker for 45 min and the same analysis is performed as with the impingers.

\section{Results}

\section{Smoke Extraction}

As can be seen in Figure 6, there is a clear indication that the extraction system prototype functions as specified in extracting the surrounding smoke produced by the smoke pencil. The main finding from this experiment is that the extraction system works extremely well when evacuating harmful plume from the smoke pencil, allowing the testing to be moved to the next phase. This finding is vital in proving that a suitable extraction system can be developed to provide extraction directly from the target area

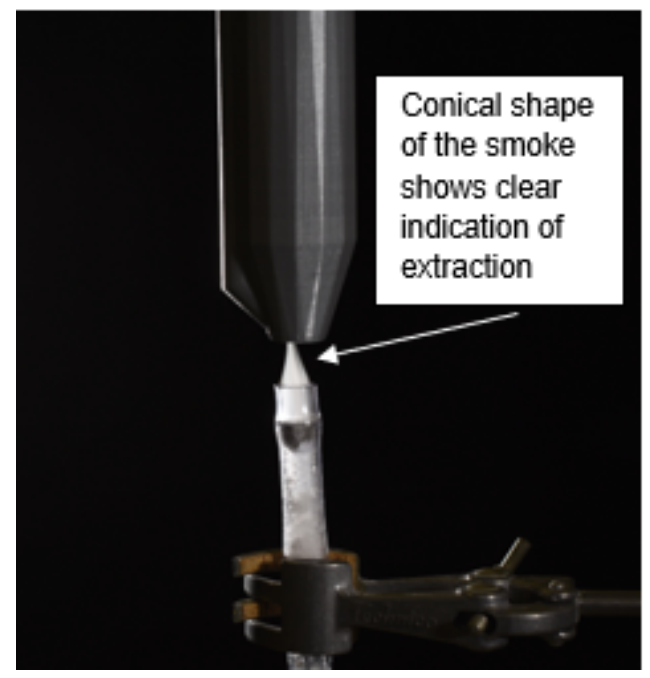

Figure 6. Smoke extraction results.

\section{Simulation of Medical Laser Procedure}

Figure 7 shows the particle size data range recorded by the OPS machine for both sets of tests. The main observation that can be made from this graph is that both lasers produce similar particle size mixtures, with the majority for both lasers falling between the $0.3 \mu \mathrm{m}$ to $0.5 \mu \mathrm{m}$ region. This can be shown through the higher percentage values of $\sim 56 \%$ for the diode and $\sim 80 \%$ for the YAG laser. Observing the trend that proceeds these values, for both sets of data the particle size percentage decreases sharply leading to a reduction in the number of particles at each larger size. This leads to the conclusion that the majority of particles emitted from laser procedures is within the $0.3 \mu \mathrm{m}$ to $0.5 \mu \mathrm{m}$ region, showing the need for effective extraction from the target area due to the potential harm particles of this size can cause to humans.

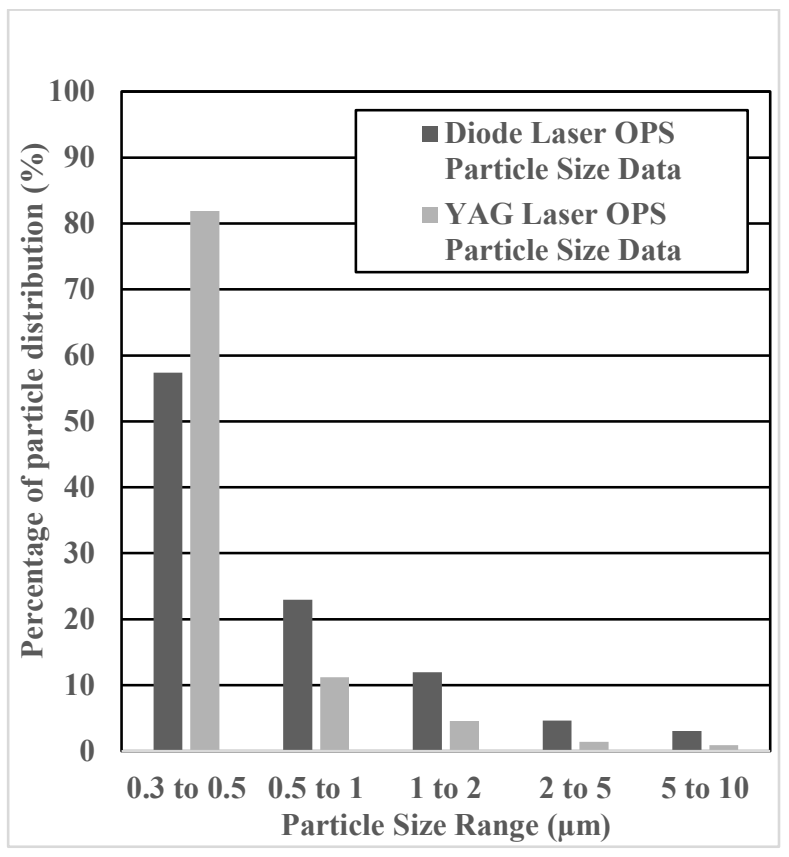

Figure 7. Simulation of Medical Procedure, Particle Size Data

Visible observations of the porcine tissue show that each laser did have differing physical effects. Figure 8 shows these effects, where the YAG laser created white 'blistered' marks and the diode laser produced black 'singe 'marks more associated with the visual effects of general burning. Anecdotally it was seen that the diode laser produced an increased visibility of plume than the YAG laser. This observation could possibly account for the varying visual defect created on the porcine tissue. The main finding from this is that even if more plume is visually observed in one instance than another, the size 
of particles emitted may be the same for both procedures as shown by Figure 7 .

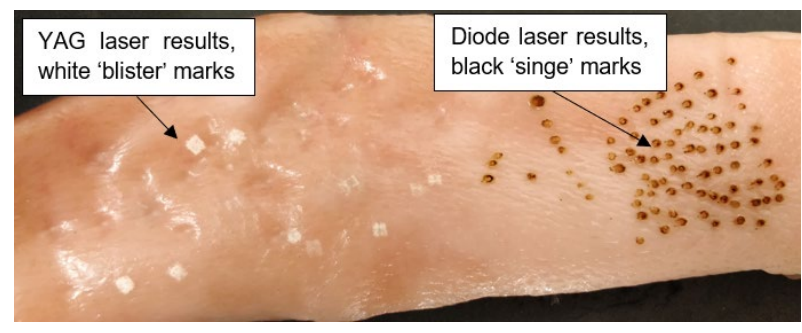

Figure 8. Simulation of Medical Laser Procedure, Visible Pork Damage

The main finding from this experiment is that the type of laser used in the procedure doe not influence the particle size generated. This is important as it shows that different physical effects, as shown in Figure 8, don't correspond with varying particle sizes being generated. This shows that data on particulate size generated is similar for these two laser types. Therefore, research can be focused on providing suitable means of extraction for the particle sizes mainly ranging in the $0.3 \mu \mathrm{m}$ to $0.5 \mu \mathrm{m}$ region, shown by Figure 7, rather than focus on varying laser effects.

\section{Bioaerosol Generation Testing}

The sampler position is defined by target area position, porcine tissue vicinity, or operator head height position. The results to focus on are those defined in the $\mathrm{cfu} / \mathrm{m}^{3}$, this shows the amount of colony forming units of the bacteria per metres cubed. Whereas the results for the filter are defined by cfu/filter. These values define the level of viability of the organisms, Bacillus globigii and MS2, following laser ablation.

\section{Bioaerosol Transmission}

As can be seen from the results in Table 1, viable Bacillus globigii were detected by both impinger and Andersen sampling, demonstrating that there was some aerosolization of microorganisms during the laser treatment process. One major finding from these results are the viability of Bacillus globigii organisms at the operator head height position. This provides key evidence that an effective extraction system is required, as the presence of the extraction prototype causes the peak reading of $51 \mathrm{cfu} / \mathrm{m}^{3}$ to almost halve in value. Viable Bacillus globigii was also detected on the filter utilised in cooperation with the extraction system as shown in Figure 9. This visual evidence supports the results in Table 1, due to the value of $13 \mathrm{cfu} /$ filter being observed. This demonstrates that some microorganisms have been bio aerosolised during laser treatment, and consequently efficiently removed via the extraction system. While the levels detected are relatively low, the important finding is that Bacillus globigii is aerosolised during the laser procedure proving the danger operators and patients can be under during laser procedures.

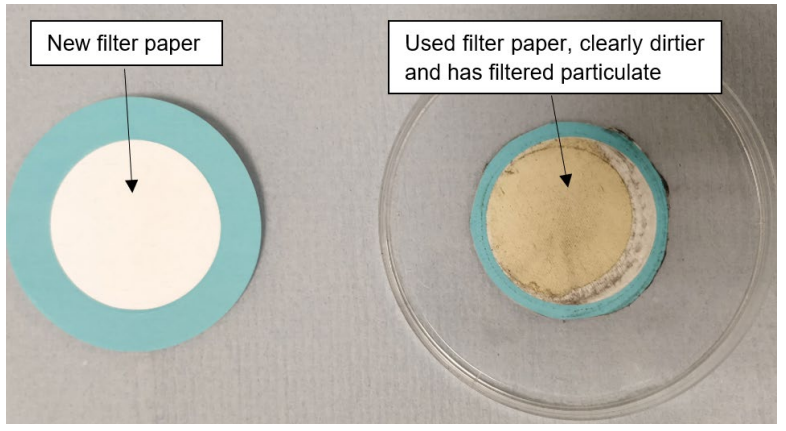

Figure 9. Bacillus Globigii In-Line Filter Results

Table 1 - Bioaerosol Generation Testing Results

\begin{tabular}{|c|c|c|c|c|c|c|}
\hline \multirow{2}{*}{ Organism } & \multirow{2}{*}{$\begin{array}{l}\text { Extraction } \\
\text { Device } \\
\text { Present }\end{array}$} & \multicolumn{2}{|c|}{ Andersen Sampler Colony Forming Units (cfu/m^3) } & \multicolumn{2}{|c|}{ Impinger Colony Forming Units (cfu/m^3) } & \multirow{2}{*}{$\begin{array}{l}\text { Whatman } \\
\text { Filter Colony } \\
\text { Forming Units } \\
\text { (cfu/filter) }\end{array}$} \\
\hline & & Target Area Position & Head-Height Position & Target Area Position & Head-Height Position & \\
\hline B.globigii & No & 32 & 51 & & & \multirow{6}{*}{13} \\
\hline B.globigii & No & 53 & 30 & 150 & 0 & \\
\hline B.globigii & No & 380 & 6 & & & \\
\hline B.globigii & Yes & 440 & 9 & & \multirow{3}{*}{1} & \\
\hline B.globigii & Yes & 280 & 19 & \multirow[t]{2}{*}{1} & & \\
\hline B.globigii & Yes & 21 & 26 & & & \\
\hline MS2 & No & 0 & 0 & \multirow{3}{*}{0} & \multirow{3}{*}{0} & \multirow{6}{*}{0} \\
\hline MS2 & No & 0 & 0 & & & \\
\hline MS2 & No & 0 & 0 & & & \\
\hline MS2 & Yes & 0 & 0 & \multirow{3}{*}{0} & \multirow{3}{*}{0} & \\
\hline MS2 & Yes & 0 & 0 & & & \\
\hline MS2 & Yes & 0 & 0 & & & \\
\hline
\end{tabular}


No airborne MS2 were detected by impinger or Andersen sampling as shown by the lack of recorded viable particles from Table 1. The initial seeding concentration of MS2 was lower than for Bacillus globigii and this may have contributed to the results. In addition, Bacillus globigii is more likely to survive aerosolization and sampling, as it is a spore-forming organism and is therefore more resistant to drying out and to the shearing forces experienced during sampling.

These results indicate that viable microorganisms can become aerosolised during the laser treatment of skin and can also survive this process. Although the degree of aerosolization is likely to vary depending on the extent of laser treatment, the number of contaminating microorganisms on the skin surface and the individual qualities of the patient. The use of effective plume removal is effective in controlling such exposures and provide improved safety to operators and patients. If the Bacillus globigii was a pathogenic organism with a low infectious dose, then this could have implications for healthcare worker exposure if inhalation exposure to the plume was not controlled. The main findings from this experiment are that viable organisms can survive laser procedures, while also still being detected at operator head height, and this shows the importance of having an effective extraction system due to the potential harm operators can be exposed to.

To protect the operators against particulate, and to also protect the patients from any particulate the operators can create through sneezing for example surgical masks can be worn. 'Surgical masks are designed to protect the working environment and not the wearer' [24]. The masks provide a six-fold reduction with viable viruses being able to be detected behind the mask, in comparison to respirators achieving a one hundred fold reduction [24]. The virus is found in aerosol droplets at less than $5 \mu \mathrm{m}$ [24], typically laser ablation has been proven to generated particles between $0.3 \mu \mathrm{m}$ [10], [25] and $0.8 \mu \mathrm{m}[26]$. This finding shows that if viable viral or bacterial organisms survive laser ablation then this can cause harm to humans. This shows that any protection currently offered to operators is not for their own safety against airborne particles. Therefore, a designed solution for extracting the fume away from the target area is vital for patient and operator safety when considering the particle sizes that can cause damage to the human respiratory system. When extraction systems are considered one of the main factors in their design is particle size and the absorption of these sizes [27]. Viruses are usually less than $0.2 \mu \mathrm{m}$ in size, whereas bacterial organisms range anywhere between 0.25 and $60 \mu \mathrm{m}[28]$.

\section{Conclusion}

- For laser skin medical procedures, patient and operator safety should be of paramount importance.

- We have shown potentially harmful particulate and viable bacterial organisms get through the entire laser process.

- The size of these emitted particles is mainly in the $0.3 \mu \mathrm{m}$ to $2.0 \mu \mathrm{m}$ region, no matter which laser form is used. This poses a threat to the health of patients, and operators who are exposed to such particulate on a more consistent basis.

\section{References}

[1] E. Alp, D. Bijl, R. P. Bleichrodt, B. Hansson, and A. Voss, "Surgical smoke and infection control," J. Hosp. Infect., vol. 62, no. 1, pp. 15, Jan. 2006.

[2] MHRA, "Lasers, intense light source systems and LEDs - guidance for safe use in medical, surgical, dental and aesthetic practices," 2015.

[3] NIOSH, "Control of Smoke From Laser/Electric Surgical Procedures," 2014.

[4] W. L. Barrett and S. M. Garber, "Surgical smoke - A review of the literature. Is this just a lot of hot air?," Surg. Endosc. Other Interv. Tech., vol. 17, no. 6, pp. 979-987, 2003.

[5] J. M. Kokosa and J. Eugene, "Chemical Composition of Laser Tissue Interaction Smoke Plume," J. Laser Appl., vol. 1, no. 3, 1989.

[6] N. Walker, J. Mathews, and N. SW, "Possible hazards from irradiation with the carbon dioxide laser," Lasers Surg. Med., vol. 6, pp. 84-86, 1986.

[7] J. Garden et al., "Papillomavirus in the vapor of carbon dioxide laser-treated verrucae," J. Am. Med. Assoc., vol. 8, pp. 1199-2029, 1988.

[8] A. Ferenczy, C. Bergeron, and R. Pichart, "Carbon dioxide laser energy disperses human papillomavirus deoxyribonucleic acid onto treatment fields," Am. J. Obstet. Gynecol., vol. 163, no. 4, pp. 1271-1274, 1990.

[9] R. Hollmann, C. Hort, E. Kammer, M. Naegele, M. Sigrist, and C. Meuli-Simmen, "Smoke in the operating theater; an unregarded source of danger," Plast. Reconstr. Surg., vol. 114(2), pp. 458-63, 2004. 
[10] I. Brüske-hohlfeld et al., "Journal of Occupational Medicine Surgical smoke and ultrafine particles," J. Occup. Med. Toxicol., vol. 6, pp. 1-6, 2008.

[11] H. Schulz et al., "Cardiovascular effects of fine and ultrafine particles," J. Aerosol Med., vol. 1, no. 8, pp. 1-22, 2005.

[12] A. J. Beswick et al., "Comparison of Multiple Systems for Laboratory Whole Room Fumigation," Appl. Biosaf., vol. 16, no. 3, pp. 139-157, Sep. 2011.

[13] MSA, "Ventilation Smoke Tube Kits Data Sheet," Sitebox, 2007. .

[14] MSA, "Material Safety Data Sheet," Sitebox, 2007. .

[15] G. M. Gray and H. J. Yardley, "Lipid compositions of cells isolated from pig, human, and rat epidermis.," J. Lipid Res., vol. 16, no. 6, pp. 434-440, 1975.

[16] U. Jacobi et al., "Porcine ear skin: An in vitro model for human skin," Ski. Res. Technol., vol. 13, no. 1, pp. 19-24, 2007.

[17] I. Dick and R. Scott, "Pig ear skin as an in-vitro model for human skin permeability.," J. Pharm. Pharmacol., vol. 44(8), no. August, pp. 640-5, 1992.

[18] F. Muhammad, J. D. Brooks, and J. E. Riviere, "Comparative mixture effects of JP-8(100) additives on the dermal absorption and disposition of jet fuel hydrocarbons in different membrane model systems," Toxicol. Lett., vol. 150, no. 150, pp. 351-365, 2004.

[19] R. C. Wester, J. Melendres, L. Sedik, H. Maibach, and J. E. Riviere, "Percutaneous absorption of salicylic acid, theophylline, 2,4dimethylamine, diethyl hexyl phthalic acid, and p-aminobenzoic acid in the isolated perfused porcine skin flap compared to man in vivo," Toxicol. Appl. Pharmacol., vol. 151, no. 1, pp. 159-165, 1998.

[20] F. P. Schmook, J. G. Meingassner, and A. Billich, "Comparison of human skin or epidermis models with human and animal skin in in-vitro percutaneous absorption," Int. J. Pharm., vol. 215, pp. 51-56, 2001.
B. Godin and E. Touitou, "Transdermal skin delivery: Predictions for humans from in vivo, ex vivo and animal models," 2007.

[22] ScienceDirect, "Bacillus Atrophaeus," ScienceDirect, 2018. .

[23] S. Duncan and J. Ho, "Estimation of viable spores in bacillus atrophaeus (BG) particles of 1 to $9 \mu \mathrm{m}$ size range," Clean - Soil, Air, Water, vol. 36, no. 7, pp. 584-592, 2008.

[24] J. Gawn, M. Clayton, C. Makison, B. Crook, and H. Hill, "Evaluating the protection afforded by surgical masks against influenza bioaerosols RR619 Evaluating the protection afforded by surgical masks against influenza bioaerosols Gross protection of surgical masks compared to," 2008.

[25] C. Nezhat, W. Winer, F. Nezhat, C. Nezhat, D. Forrest, and R. WG, "Smoke from laser surgery; is there a health hazard?," Lasers Surg. Med., vol. 7, no. 4, pp. 376-82, 1987.

[26] N. Mowbray, J. Ansell, N. Warren, P. Wall, and J. Torkington, "Is surgical smoke harmful to theater staff? a systematic review."

[27] J. Tyrer, "It is possible to make hand delivered medical / cosmetic laser equipment inherently safe," Int. Laser Saf. Conf., pp. 198-204, 2013.

[28] R. Sturm, "Bioaerosols in the lungs of subjects with different ages-part 1: deposition modeling," Ann Transl Med, vol. 4, no. 11, 2016. 